\title{
MACROKINETIC INVESTIGATIONS OF DRY FLUE-GAS DESULFURIZATION PROCESS USING TGA TECHNIQUE
}

\author{
SIMION DRĂGANa
}

\begin{abstract}
In this paper, a kinetic study about of dry flue-gas desulfurization process was investigated. Experimental thermogravimetric measurements, employing a CAHN TG- 121 system, have been performed on the reaction of sulfur dioxide and oxygen with calcined limestone. The conversions versus time of calcined limestone, ranging in particle size from 25 to $450 \mu \mathrm{m}$, were measured over the temperature range $973-1173 \mathrm{~K}$ and a gas rate of 0.046 $\mathrm{m} / \mathrm{s}$. The influence of kinetic parameters on the sulfation process has been tracked. A significant influence is the temperature at which the sulfation and the size of the adsorbent granules are achieved. Processing the experimental results in Ink $\mathrm{k}_{1, \mathrm{II}} \mathrm{T}^{-1}$ coordinates allowed the determination of the activation energy and the establishment of the corresponding mechanisms. The results, $\mathrm{Ea}>42 \mathrm{KJ} / \mathrm{mol}$ for the both indicate that the sulfation process is carried out according to the macrokinetic mass transformation model, only for small granules of the solid with $\mathrm{dp}<25 \mu \mathrm{m}$ and temperatures $\mathrm{T}>973 \mathrm{~K}$ ) are the limiting ones the process. At higher granulations of the solid particles, the activation energy values $\mathrm{Ea}<<42 \mathrm{~kJ} / \mathrm{mol}$, emphasizes that limitative of the global process are the inner/outer diffusion phenomena shown that the sulfation process follows the transfer macrokinetic model.
\end{abstract}

Keywords: dry desulfurization process, sulfation process, transfer and mass transformation macrokinetic model.

\section{INTRODUCTION}

Industrial development and the economic progress have been accompanied by a growing energy demand. Majority of energy production is obtained by burning fossil fuels with variable sulfur content. International Energy Agency estimates that fossil fuels will still play a key role in total energy production for the years to come. Has estimated that fossil fuels will continue to supply almost $80 \%$ of world energy use until 2040 , and according to the

\footnotetext{
a Universitatea Babeş-Bolyai, Facultatea de Chimie şi Inginerie Chimică, Str. Kogălniceanu,
} Nr. 1, RO-400084 Cluj-Napoca, Romania, sdragan@chem.ubbcluj.ro 
World Energy Council, this might be prolonged to 2050 [1]. The combustion of coal and oil supply a significant part of the world's present energy demand and caused emissions of gas pollutants which released into the atmosphere affects the quality of the environment. An important particular case, with a major environmental impact, is the emissions of $\mathrm{SO}_{2}$, which is considered as one of the gravest chemical threats to the global environment [1-4].

The industrial sectors that contribute to the $\mathrm{SO}_{2}$ emissions are the metallurgical ore refining and the power industry that use fossil fuels as raw material. Sulfur dioxide emissions are harmful both to the environment and to human health, therefore the problem of desulfurization gaseous emissions from burning fossil fuels is very important. These industrial sectors continue to come under pressure from both national and local regulatory groups to reduce sulfur dioxide emissions. With trend in the industry, retrofit technologies are likely to play an important role in any $\mathrm{SO}_{2}$ emission reduction strategy. Emissions of $\mathrm{SO}_{2}$ can be controlled in several ways: switch to a fuel that has lower sulfur content, or improve the efficiency of the industrial process so that less fuel is required. The sulfur in the fuel can in principle be removed before use; however, in practice, it is uneconomic to remove more than a small percentage of the sulfur. In many applications, the most efficient means of controlling $\mathrm{SO}_{2}$ emissions is to remove the $\mathrm{SO}_{2}$ from the flue gases before they are released to the atmosphere.

Several different flue gas desulfurization (FGD) technologies have been developed for this aim. This is the main reason why the issue of flue-gas desulfurization has become very topical and is the theme of numerous researches in this field [5-10].

In the last decade, technology of flue gas desulfurization has made considerable progress in terms of efficiency, reliability and those are classified into three main processes: dry, semi-dry and wet [5]. Independently of the classification, most of specialized literature [1-8] agrees on the fact that the wet limestone FGD system is the FGD process most widely used (87\%) because of its high desulfurization performance and low operating cost [5]. In dry and/or semi-dry FGD systems, $\mathrm{SO}_{2}$-containing flue gas reacts with an alkaline sorbent typically $\mathrm{Ca}(\mathrm{OH})_{2}$ or $\mathrm{CaO}$. Spray dry is the second most popular FGD system worldwide and mostly used for relatively small to medium capacity boilers using low to medium S (1.5 wt.\%) coal. A comparative analysis of these shows that the process based on the solid-gas reaction using lime produced in situ by spraying fine grain limestone directly into the furnace (firing zone) is the process recommended for plants with a capacity less than 100 $\mathrm{MWh}$ in operation. It is simple to implement and exploited it does not require complex equipment. The main deficiency of the process consists in the low degree of use of lime, the large amount of waste that is difficult to recover, which poses problems of storage. 
During the years, a number of investigations have been made on the kinetics of the reaction of $\mathrm{SO}_{2}$ with limestone in the dry desulfurization processes. Two major directions have been investigated: the effect of various process variables on the reaction rate and identification of the reaction mechanism with the help of a suitable model. The adsorption of $\mathrm{SO}_{2}$ by limestone involves two consecutive reaction steps: (a) dissociation of calcium carbonate and (b) reaction of $\mathrm{CaO}$ with $\mathrm{SO}_{2}$. The rate of this second step is the important factor in all the pollution-control processes. Depending on the reactor temperature, reaction mechanisms of direct $\left(\mathrm{CaCO}_{3}\right)$ or indirect $(\mathrm{CaO})$ sulfation of the limestone may occur [11]. It has been demonstrated that indirect sulfation reached the highest efficiency of desulfurization [12, 13].

Current research aims to establish the process mechanism and increase the use of lime and improve the $\mathrm{SO}_{2}$ retention efficiency. In this paper a kinetic study to show the influence of the main parameters (temperature and solids particle size) of the desulfurization process. Based on experimental measurements were calculated rate constants and activation energies. Numeric values of activation energy provide indications of the macro-kinetic mechanism of the global dry desulfurization process.

Process chemistry: The chemisorption process in the $\mathrm{CaO}-\mathrm{SO}_{2}$ system is complex by the many transformation and transfer processes involved. The mass transformation processes that take place can be described by the reactions:

$$
\begin{aligned}
& \mathrm{SO}_{2[] g} \leftrightarrow \mathrm{SO}_{2} \text { ads } \\
& \mathrm{SO}_{2} \text { ads }+\mathrm{CaO}_{[]] s} \stackrel{t<600^{\circ} \mathrm{C}}{\longrightarrow} \mathrm{CaSO}_{3} \\
& \mathrm{CaSO}_{3} \stackrel{t: 600-680^{\circ} \mathrm{C}}{\longrightarrow} \mathrm{CaO}+\mathrm{SO}_{2} \\
& 4 \mathrm{CaSO}_{3} \stackrel{t>680^{\circ} \mathrm{C}}{\longrightarrow} 3 \mathrm{CaSO}_{4}+\mathrm{CaS} \\
& 3 \mathrm{CaSO}_{4}+\mathrm{CaS} \stackrel{t>900^{\circ} \mathrm{C}}{\longrightarrow} 4 \mathrm{CaO}+4 \mathrm{SO}_{2}
\end{aligned}
$$


It is noticed that $\mathrm{CaSO}_{4}$ formation is possible in the absence of oxygen at temperatures above $680^{\circ} \mathrm{C}$. At temperatures above $900^{\circ} \mathrm{C}, \mathrm{CaSO}_{4}$ can react with $\mathrm{CaS}$ when are recovered $\mathrm{CaO}$ and $\mathrm{SO}_{2}$. The presence of excess oxygen in the combustion air promotes the chemisorption process as $\mathrm{CaSO}_{3}$ and it reacts with CaS according to the reactions:

$$
\begin{aligned}
& \mathrm{CaSO}_{3}+1 / 2 \mathrm{O}_{2} \rightarrow \mathrm{CaSO}_{4} \\
& \mathrm{CaS}+\mathrm{O}_{2} \rightarrow \mathrm{Ca}+\mathrm{SO}_{2} \\
& \mathrm{CaS}+3 / 2 \mathrm{O}_{2} \rightarrow \mathrm{CaSO}_{3}
\end{aligned}
$$

\section{RESULTS AND DISCUSSION}

The $\mathrm{CaO}$ sulfation degree was determined with the relationship deduced from the mass balance equations for the solid phase:

$$
\begin{aligned}
& m_{\mathrm{CaO}}=m_{\mathrm{CaO}}^{0}-m_{\mathrm{CaO}}^{0} \cdot \eta_{\mathrm{CaO}} \\
& m_{\mathrm{CaSO} 4}=0+\frac{M_{\mathrm{CaSO}}}{M_{\mathrm{CaO}}} \cdot m_{\mathrm{CaO}}^{0} \cdot \eta_{\mathrm{CaO}} \\
& m_{A^{\prime \prime}}=m_{A^{\prime \prime}}^{0} \\
& m_{[] s}=m_{[] s}^{0}\left(1+\frac{80}{56} \bar{x}_{C a O}^{0} \cdot \eta_{C a O}\right) \\
& \eta_{C a O}=\frac{56}{80} \cdot \frac{\Delta m_{[] s}}{m_{[] s}^{0} \cdot \bar{x}_{C a O}^{0}}
\end{aligned}
$$

The influence of temperature on the lime sulfation process for the three solid granulation classes used is shown in Figures 1-3. 
MACROKINETIC INVESTIGATIONS OF DRY FLUE-GAS DESULFURIZATION PROCESS ...

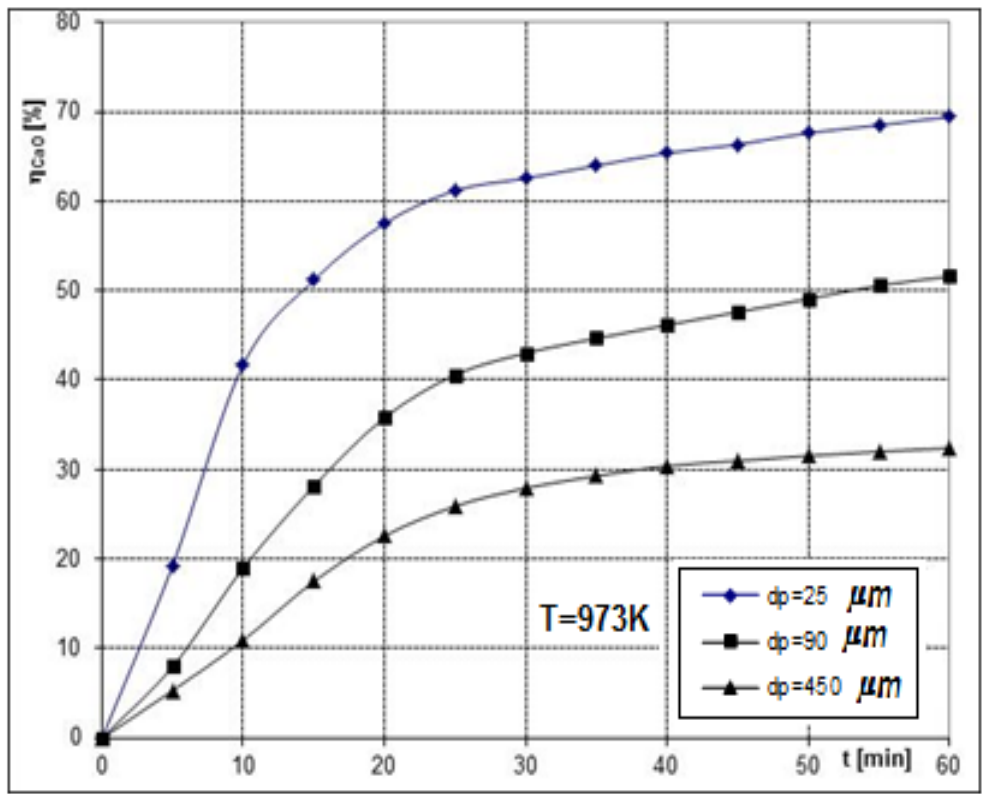

Figure 1. Influence of solid size on sulfation at temperature $=973 \mathrm{~K}$

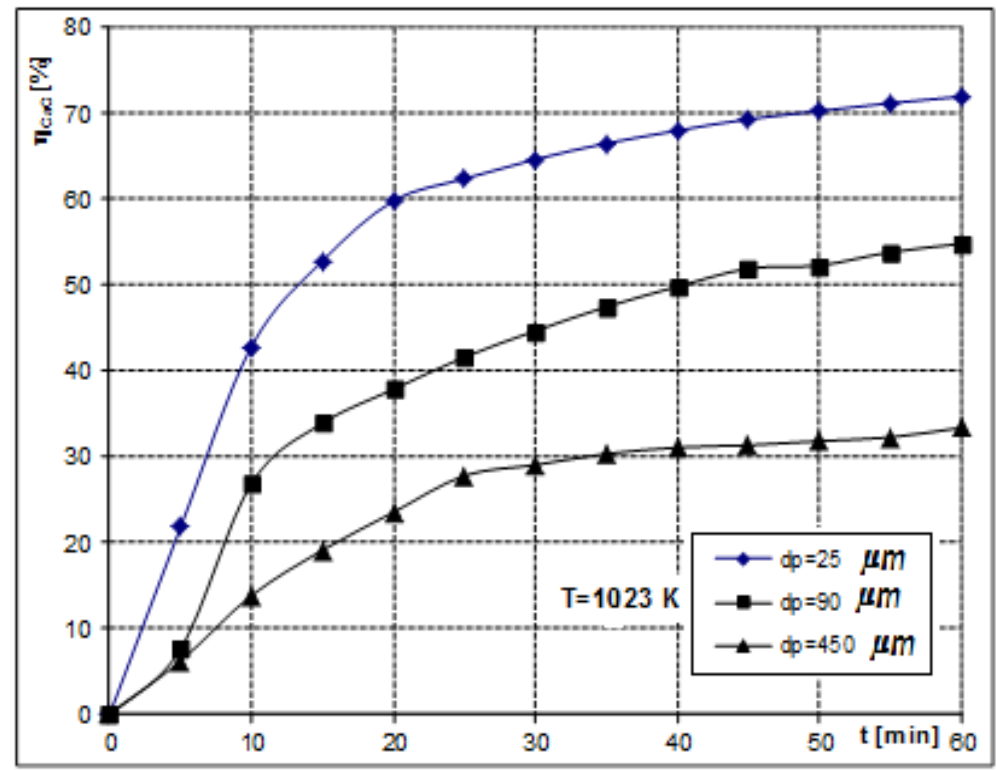

Figure 2. Influence of solid size on sulfation at temperature $=1023 \mathrm{~K}$ 


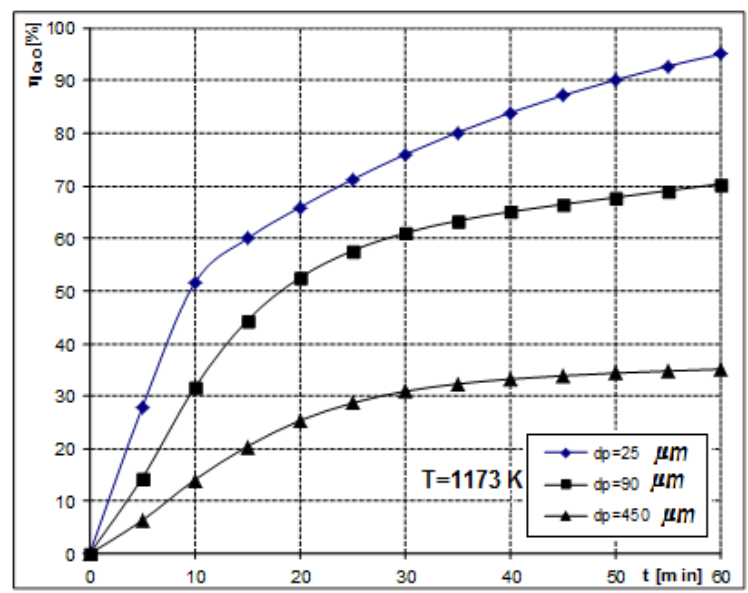

Figure 3. Influence of solid size on sulfation at $\mathrm{T}=1173 \mathrm{~K}$

Temperature has a strong influence on the degree of sulfation in the case of the solids with $25 \mu \mathrm{m}$ grains size. For solid particles with $\mathrm{dp} \leq 25 \mu \mathrm{m}$, the sulfation degree increases from $70 \%$ at $\mathrm{T}=973 \mathrm{~K}$ to $90 \%$ at $\mathrm{T}=1173 \mathrm{~K}$.

From Figures 1-3 it can be seen that the rate of the sulfation process is greatly reduced after the first 15 minutes, for the grain size $d p \geq 25 \mu \mathrm{m}$.

The influence of the solid particle size on the sulfatation rate at different time and constant temperatures is shown in Figures 4-6.

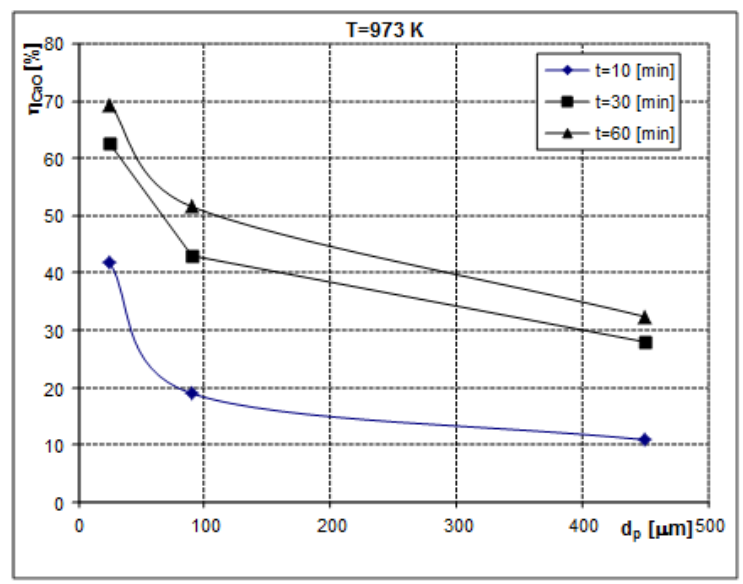

Figure 4. Influence of solid size on sulfation at $\mathrm{T}=973 \mathrm{~K}$ at different time intervals 
MACROKINETIC INVESTIGATIONS OF DRY FLUE-GAS DESULFURIZATION PROCESS ...

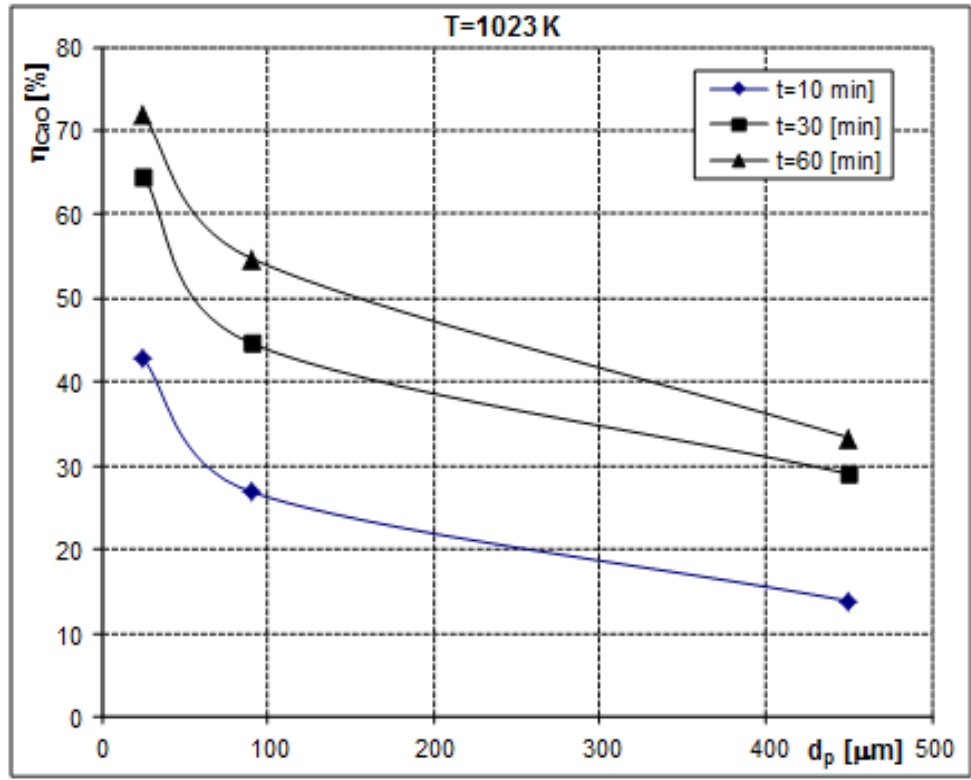

Figure 5. Influence of solid size on sulfation at $\mathrm{T}=1023 \mathrm{~K}$ at different time intervals

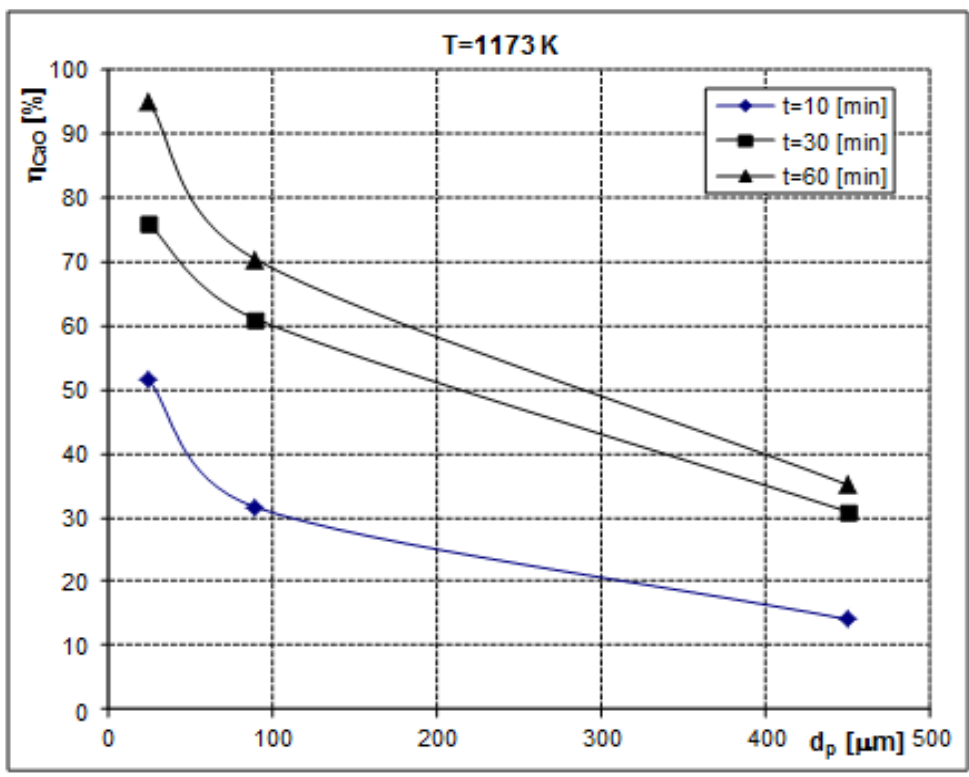

Figure 6. Influence of solid size on sulfation at temperature $=1173 \mathrm{~K}$ at different time intervals 
The diameter of the solid particles have a significant influence on the sulfation degree of lime, only for the solid particle size of $d p \leq 25 \mu \mathrm{m}$, degree of sulfation is technologically acceptable when $\eta_{\mathrm{CaO}}=95 \%$ at $\mathrm{T}=1173 \mathrm{~K}$. For the grains solids with $\mathrm{dp} \geq 90 \mu \mathrm{m}$, the sulfation degree decreases significantly, so that for particles with $\mathrm{dp}=450 \mu \mathrm{m}$ the sulfation degree of lime does not exceed $35 \%$ even at $\mathrm{T}=1173 \mathrm{~K}$. Influence of the granulation of the solid on the sulfation degree of lime depends on the working temperature only for the solid particles with $\mathrm{dp} \leq 25 \mu \mathrm{m}$.

The experimental data obtained for evolution in time of the sulfation degree of lime shown in Figures 1-3 was used to calculate the rate constants of sulfation $\mathrm{k}$, based on the following equation:

$$
\begin{aligned}
& -\frac{d C_{C a O}}{d t}=k C_{C a O} \\
& -\frac{d C_{C a O}}{C_{C a O}}=k d t \\
& C_{C a O}=C_{C a O}^{0}\left(1-\eta_{C a O}\right)
\end{aligned}
$$

The integration of the equation for the boundary conditions leads to the expression specified: $-\ln \left(1-\eta_{\mathrm{CaO}}\right)=\mathrm{k}$ t. To determine the constants rate of the process of sulfation, have been represented the diagrams from Figures 7-9 in coordinate (1- $\left.\eta_{\mathrm{caO}}\right)-\mathrm{t}$.

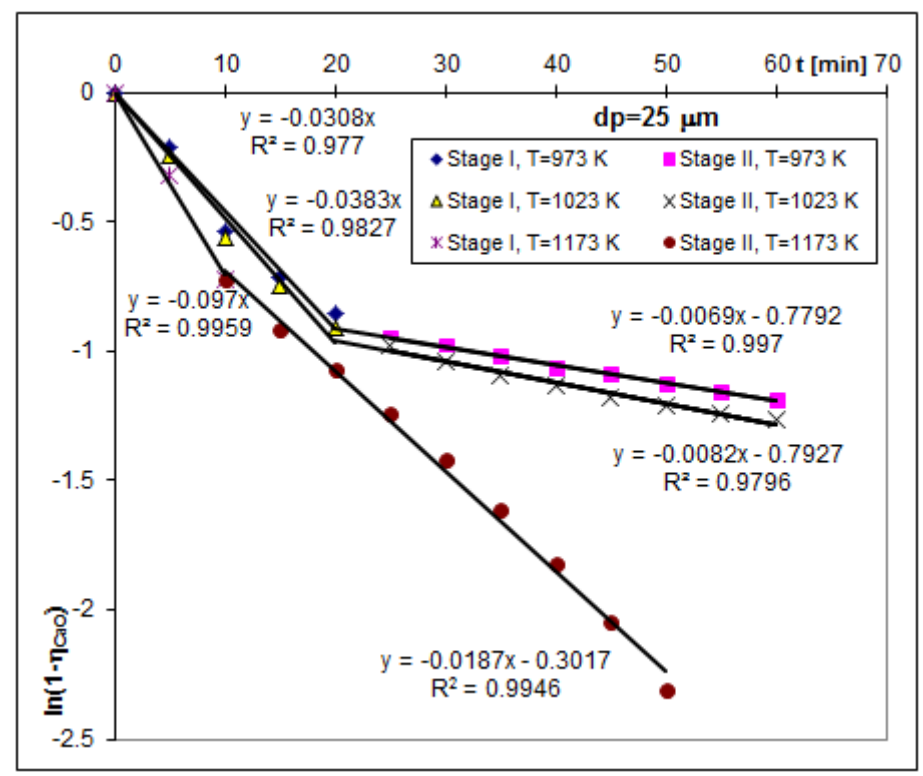

Figure 7. Determination of the rate constants for grain solids with $\mathrm{dp}=25 \mu \mathrm{m}$ 
MACROKINETIC INVESTIGATIONS OF DRY FLUE-GAS DESULFURIZATION PROCESS ...

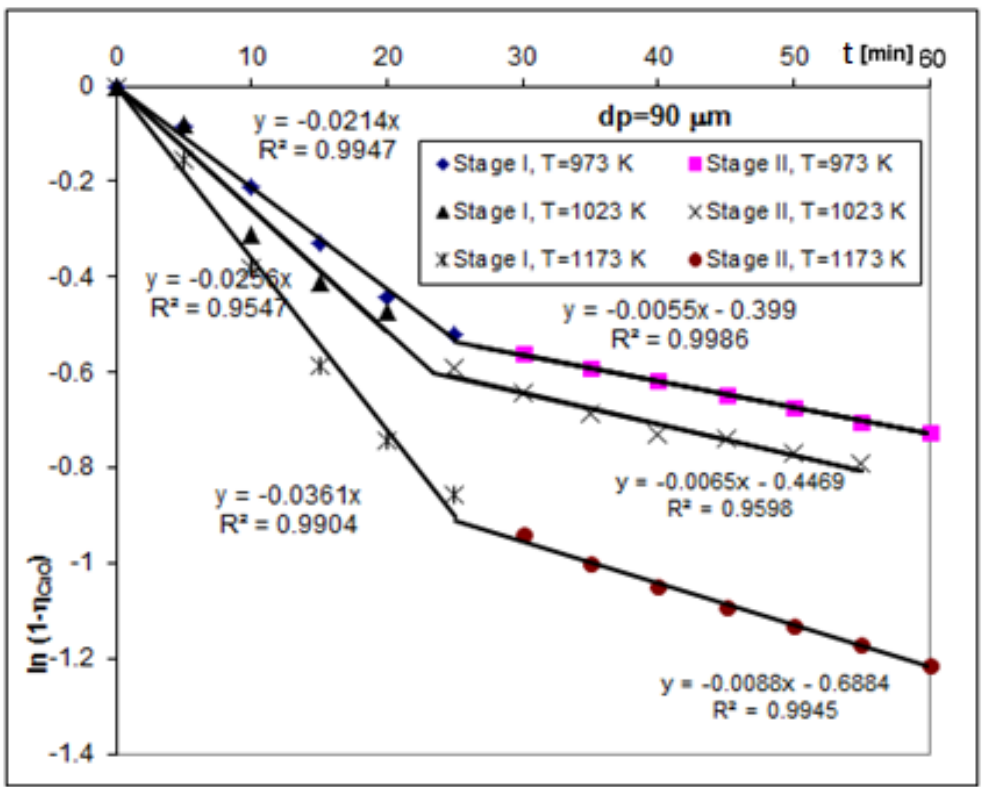

Figure 8. Determination of the rate constants for grain solids with $\mathrm{dp}=90 \mu \mathrm{m}$

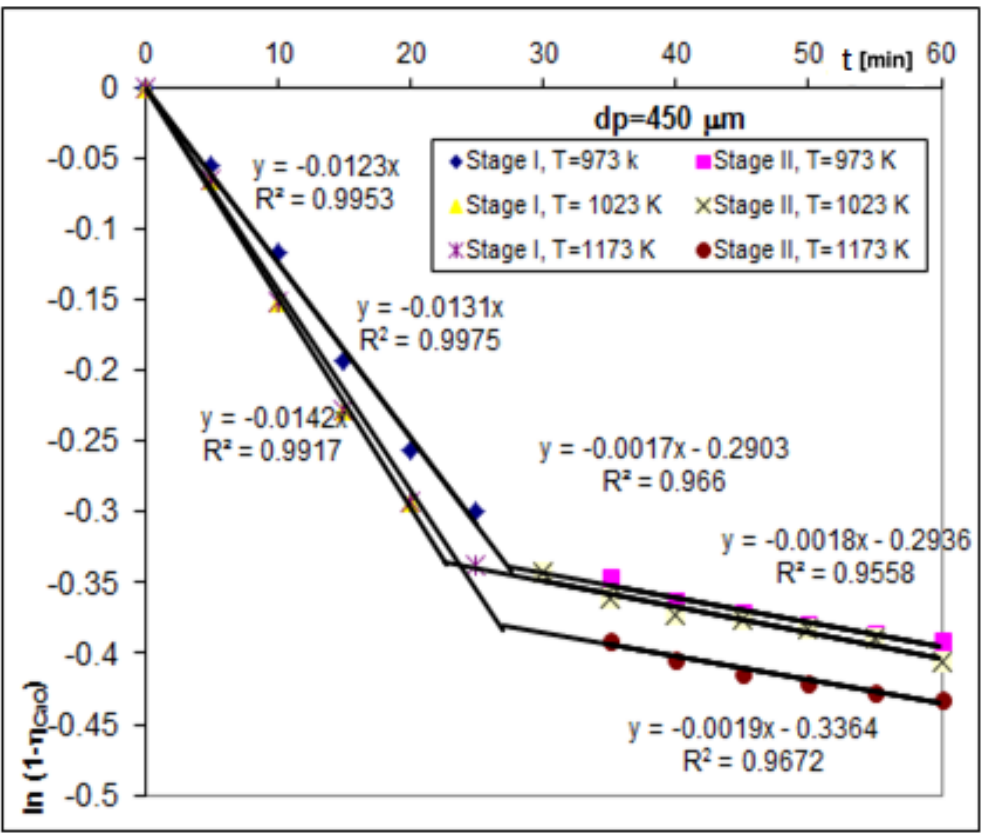

Figure 9. Determination of the rate constants for grain solids with $\mathrm{dp}=450 \mu \mathrm{m}$ 
From the slope of the straight lines were obtained the values of the rate constants, that were used to determine the activation energies of by their graphic processing in the coordinates Ink-1/T, according to the diagrams shown in figure 10-12.

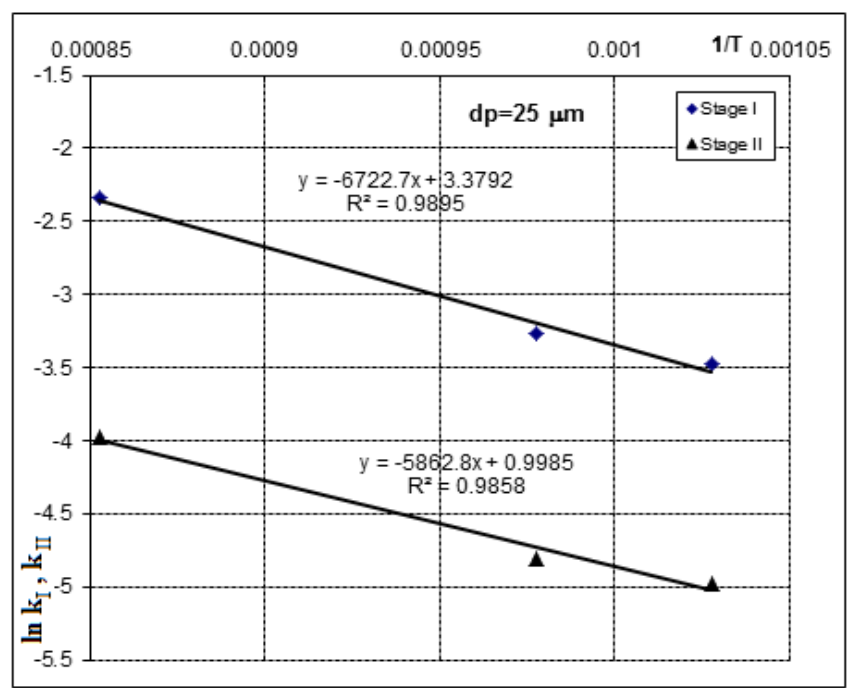

Figure 10. Determination the activation energies for solids with $\mathrm{dp}=25 \mu \mathrm{m}$

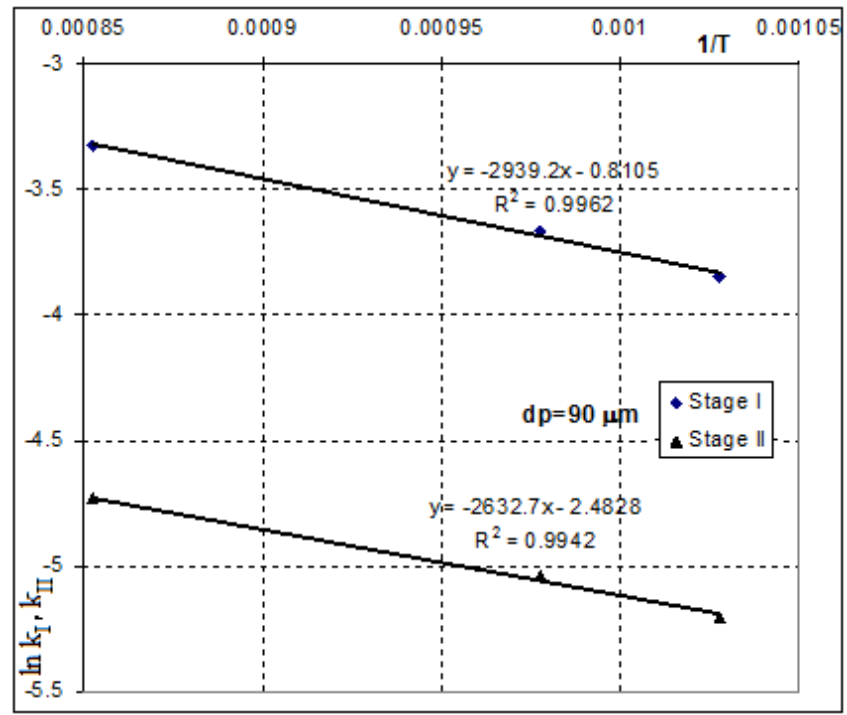

Figure 11. Determination the activation energies for solids with $\mathrm{dp}=90 \mu \mathrm{m}$ 
MACROKINETIC INVESTIGATIONS OF DRY FLUE-GAS DESULFURIZATION PROCESS ...

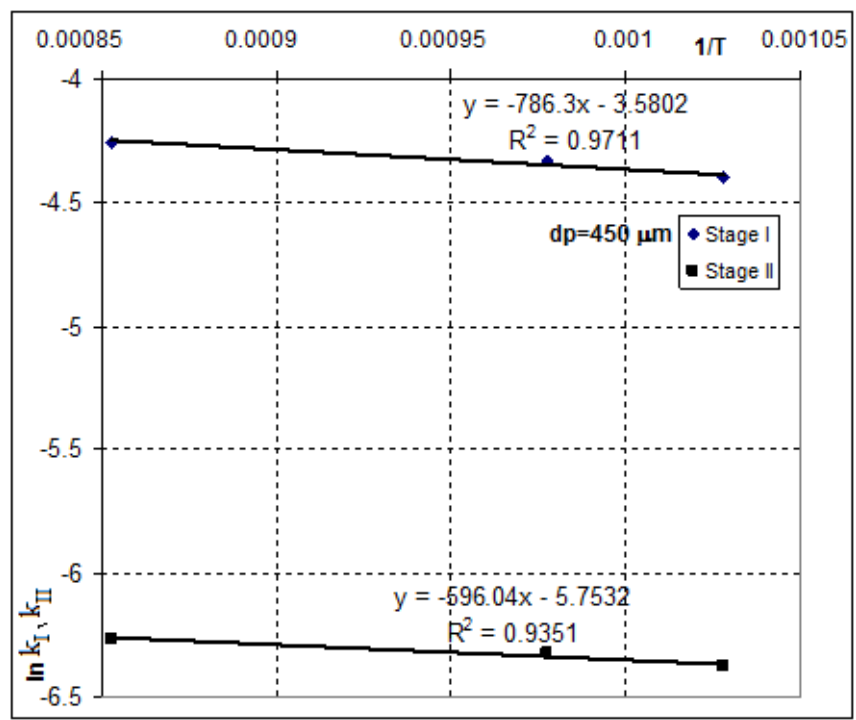

Figure 12. Determination the activation energies for solids with $\mathrm{dp}=450 \mu \mathrm{m}$

The diagrams analysis suggests a change in the macrokinetic mechanism by which the global desulfurisation process takes place in time.

The numerical values of the rate constants and activation energies corresponding to the two stage of the sulfation process of under the working conditions are shown in Table1.

Table 1. The constants rate $\mathrm{k}$ and activation energies $\mathrm{Ea}$

\begin{tabular}{|c|c|c|c|c|c|c|}
\hline \multirow{2}{*}{$\begin{array}{c}\mathrm{dp} \\
{[\mu \mathrm{m}]}\end{array}$} & \multirow{2}{*}{$\mathrm{k}$} & \multicolumn{3}{|c|}{$\mathrm{T}[\mathrm{K}]$} & \multicolumn{2}{c|}{$\mathrm{Ea}[\mathrm{Kj} / \mathrm{mol}]$} \\
\cline { 3 - 6 } & & 973 & 1023 & 1173 & $\mathrm{I}$ & $\mathrm{II}$ \\
\hline \multirow{2}{*}{25} & $\mathrm{k}_{\mathrm{I}}$ & 0.0308 & 0.0383 & 0.0971 & 55.92 & 48.76 \\
\cline { 2 - 5 } & $\mathrm{k}_{\|}$ & 0.0069 & 0.0082 & 0.0187 & & \\
\hline \multirow{2}{*}{90} & $\mathrm{k}_{\mathrm{I}}$ & 0.0214 & 0.0256 & 0.0361 & 21.9 & 21.51 \\
\cline { 2 - 5 } & $\mathrm{k}_{\|}$ & 0.0055 & 0.0065 & 0.0088 & & \\
\hline \multirow{2}{*}{450} & $\mathrm{k}_{\mathrm{I}}$ & 0.0123 & 0.0131 & 0.0142 & \multirow{2}{*}{6.54} & 4.95 \\
\cline { 2 - 5 } & $\mathrm{k}_{\|}$ & 0.0017 & 0.0018 & 0.0019 & & \\
\hline
\end{tabular}

It can be seen that the values of the rate constants increase with increasing temperature and decrease with increasing solid grain size. For the stage I corresponding to the start-up of the process, the constants rate $k_{\mathrm{l}}$ are much higher than the constant rate $k_{\|}$corresponding to the final stage of the process. 
The analysis of the sulfation process based on the activation energies Ea shows that it is carried out according to the macrokinetic mass transformation model, only for small granules of the solid with $\mathrm{dp}<25 \mu \mathrm{m}$ and temperatures T> $973 \mathrm{~K}$, where Ea has values higher than $42 \mathrm{Kj} / \mathrm{mol}$. At higher granulations of the solid, the activation energy values shown that the sulfation process follows the pore-transfer macrokinetic model. The molar volume of $\mathrm{CaSO}_{4}$ that is formed is greater than the molar volume of the solid reagent, thus decreases the porosity of the solid. Thus, the Knudsen diffusion stage is passed, the share of mass transformation processes in the global process is decreasing, as evidenced by the strong decrease in the value of activation energies.

In the diffusion stage, the weight of mass transformation processes in the global process is decreasing, as evidenced by the strong decrease the activation energies.

\section{CONCLUSIONS}

The dry injection of limestone fine particles in the power plant furnaces is the second most commonly used process for flue gas desulfurization and acid rain mitigation. The limestone is quickly converted to lime which further reacts with sulfur dioxide. The complete calcination is a key factor for higher desulfurization efficiency.

The effect of the principal variables affecting sulfur dioxide retention (temperature and solid particle size) and macrokinetic mechanism have been investigated with TGA technique. The influence of temperature on the conversion of solid particles, at a given time, is rather significant. This may suggest a transformation rate-determining step, with a great activation energy. Temperature has a strong influence on the degree of sulfation in the case of the solids with $25 \mu \mathrm{m}$ grains size. The diameter of the solid particles have a significant influence on the sulfation degree of lime. The sulfation reaction rate increase with decreasing sorbent particle size and increasing with temperature.

It can be observed that the sulfation process was performed by two stages. It is carried out according to the macrokinetic mass transformation model, only for small granules of the solid with $\mathrm{dp}<25 \mu \mathrm{m}$ and temperatures $\mathrm{T}>973 \mathrm{~K}$. where activation energy Ea has values higher than $42 \mathrm{Kj} / \mathrm{mol}$.

The first stage was controlled by chemical reaction and/or diffusion through porous system of the particle. As the reaction proceeded, the pore volume of solid has decreased due to molar volume of the product (CaSO4) was higher than reagent solid $(\mathrm{CaO})$ and as a result the external pores were plugged. In this moment, the second stage began and it was controlled by diffusion through reaction product layer. 


\section{EXPERIMENTAL SECTION}

The experimental study was carried out with CAHN-TG 121, provided with a data acquisition and control DACS system, shown in Figure 13.

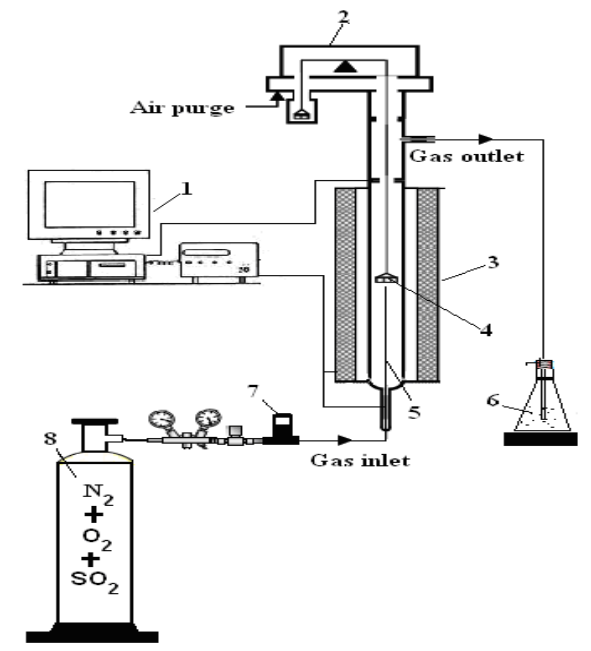

Figure 13.The schematic of the experimental setup for the $\mathrm{SO} 2$ chemisorption on the solid $\mathrm{CaO}$

The solid adsorbent used was $\mathrm{CaO}$, obtained by calcination of Sandulesti (Turda) limestone, whose the chemical composition is shown in Table 2.

Table 2. Chemical composition of limestone

\begin{tabular}{|c|c|c|c|c|c|}
\hline Component & $\mathrm{CaCO}_{3}$ & $\mathrm{Fe}_{2} \mathrm{O}_{3}$ & $\mathrm{Al}_{2} \mathrm{O}_{3}$ & $\mathrm{SiO}_{2}$ & $\mathrm{MgCO}_{3}$ \\
\hline$(\%)$ & 96.5 & 1.8 & 0.86 & 0.33 & 0.5 \\
\hline
\end{tabular}

Three granulation limestone classes were used, with: $\mathrm{dp}=0-50 \mu \mathrm{m}$; $\mathrm{dp}=80-100 \mu \mathrm{m} ; \mathrm{dp}=400-500 \mu \mathrm{m}$. The carbonate decomposition was carried out by heating at $T=973 \mathrm{~K}$ and pressure $p=0.34$ bar for $40 \mathrm{~min}$ to constant mass, then the resulting samples were brought into contact with the gaseous mixture with the concentration of $0.9 \% \mathrm{SO} 2$ and circulation rate of $0.046 \mathrm{~m} / \mathrm{s}$. The evolution of decomposition and sulfation processes was followed by sample mass variation and recorded in the form of thermograme of the type shown in Figure 14. 


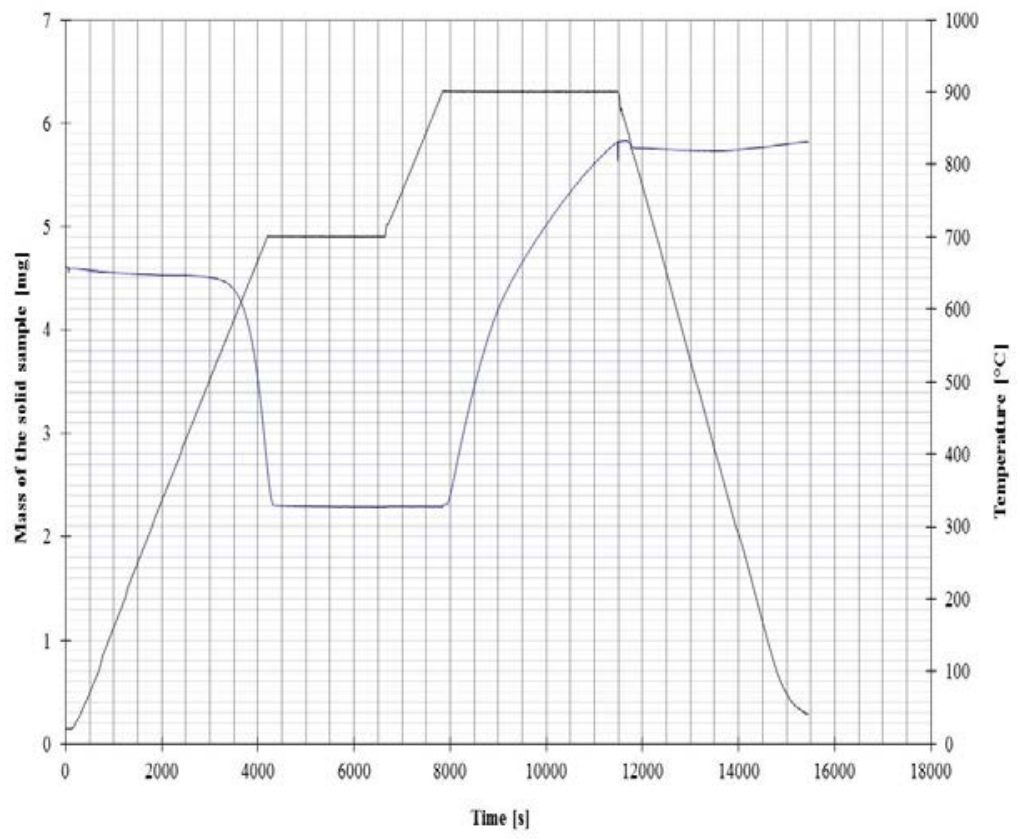

Figure 14. The evolution of limestone decomposition and the sulfation process

\section{REFERE NCES}

1. R. del Valle-Zermeno, Formosa J. and Chimenos J.M., Reviews in Chemical Engineering, 2015, 31 (4), 303.

2. A. Franco and A.R. Diaz , Energy, 2009, 34(3), 348.

3. T. Hlincik, P. Buryan, Fuel 2013a; 104; 208.

4. T. Hlincik, P. Buryan Fuel Process Technol. 2013b, 111, 62.

5. P. Córdoba, Fuel, 2015, 144, 274.

6. S. Drăgan, STUDIA Universitatis Babeş-Bolyai, Chemia, 2017, 62 (4), 283.

7. R. del Valle-Zermeno, J. Formosa, J.A. Aparicio, M. Guembe, J.M. Chimenos. Fuel Process Technol., 2015, 138, 30.

8. L. Marocco, A. Mora, Separation and Purification Technology, 2013, 108, 205.

9. S. Drăgan, Al. Ozunu, Central Eurpean Journal of Chemistry, 2012, 10 (5), 1556.

10. Z. Zhu, Y. Ma, Z. Qu, L. Fang, W. Zhang, N Yan, Fuel, 2017, 195, 33.

11. F. de Souza and S.R. Bragança, ,Brazilian Journal of Chemical Engineering, 2017,34 (1), 263.

12. D. Diego, L.F. Rufas, A. García-Labiano, F. de Las Obras-Loscertales, M. Abad, A. Gayán, P., Adánez, Fuel, 2013,114, 106.

13. F. de Souza, S.R. Bragança, Thermochimica Acta, 2013, 561, 19. 